\title{
Duodenal Decubitus Ulcer Caused by Percutaneous Endoscopic Transgastric Jejunostomy Tube
}

\author{
Seokin Kang', Yuri Kim', Hee Kyong Na', Sun Ju Chung ${ }^{2}$, Jeong Hoon Lee ${ }^{1}$ \\ Departments of Gastroenterology ${ }^{1}$ and Neurology ${ }^{2}$, Asan Medical Center, University of Ulsan College of Medicine, Seoul, Korea
}

Percutaneous endoscopic gastrostomy (PEG) has substituted surgical gastrostomy for long-term enteral nutrition. Percutaneous endoscopic transgastric jejunostomy (PEG-J) entails placing a feeding tube into the jejunum through PEG. Unlike PEG, PEG-J is associated with complications caused by the jejunal extension tube. Herein, we report a rare complication of PEG-J. A 71-year-old woman who underwent PEG-J for the administration of carbidopa-levodopa, complained of epigastric pain, dyspepsia, and weight loss of more than 10\% in 2 months. Esophagogastroduodenoscopy revealed a duodenal decubitus ulcer caused by the pressure from the jejunal extension tube. After removal of the PEG-J and a 4-week treatment with a proton pump inhibitor, the ulcer healed and the symptoms resolved. (Korean J Helicobacter Up Gastrointest Res 2020;20:324-327)

Key Words: Duodenal ulcer; Gastrostomy; Jejunostomy; Pressure ulcer

\section{INTRODUCTION}

Percutaneous endoscopic gastrostomy (PEG) was first described by Gauderer et al. ${ }^{1}$ in 1980. PEG substituted surgical gastrostomy for long-term enteral nutrition. Percutaneous endoscopic transgastric jejunostomy (PEG-J) was introduced by Ponsky and Aszodi ${ }^{2}$ in 1984 for feeding-related problem including aspiration pneumonia caused by reflux of gastric contents. PEG-J is to place a jejunal extension tube through a PEG into the jejunum. ${ }^{3}$ PEG-J has complications PEG does not have such as kinking and knotting of distal end of the jejunal extension tube. ${ }^{4-7}$ Herein, we report another rare complication of PEG-J, which is duodenal decubitus ulcer caused by the long-term pressure from the jejunal extension tube.

\section{CASE REPORT}

A 71-year-old woman visited the outpatient clinic with complaining of epigastric pain, dyspepsia, and weight loss more than $10 \%$ in 2 months ( $56 \mathrm{~kg}$ to $50 \mathrm{~kg}$ ). She was diagnosed with idiopathic Parkinson's disease 15 years ago

Received: May 18, 2020 Revised: June 16, 2020 Accepted: June 18, 2020

Corresponding author: Jeong Hoon Lee

Department of Gastroenterology, Asan Medical Center, University of Ulsan College of Medicine, 88 Olympic-ro 43-gil, Songpa-gu, Seoul 05505, Korea

Tel: +82-2-3010-5678, Fax: +82-2-476-0824, E-mail: jhlee.gi@amc.seoul.kr and she had no other underlying diseases. The patient underwent PEG-J (15-Fr Freka ${ }^{\circledR}$ PEG Gastric Set ENFit ${ }^{\circledR}$ and 9-Fr Freka ${ }^{\circledR}$ Intestinal Tube; Fresenius Kabi Ltd., Cheshire, United Kingdom) 7 months ago for receiving carbidopa-levodopa infusion gel directly into the jejunum. During the procedure, no abnormal lesions on the esophagus, stomach, and duodenum were observed and there was no acute complication. She used PEG-J only for carbidopa-levodopa infusion gel and maintained food ingestion via mouth.

There was no adverse event except an episode of PEG-J insertion site infection 4 months ago. It was cured after prescription of cefradine $500 \mathrm{mg}$ three times a day by mouth for 2 weeks.

Physical examination revealed no specific abnormalities, and laboratory or imaging tests were not carried out. She was prescribed gastrointestinal motility modifying agents for a month. However, her symptoms persisted, and she developed postprandial epigastric pain.

Esophagogastroduodenoscopy (EGD) was performed. The inner bolster was expelled in the pylorus (Fig. 1A). A deep and large longitudinal ulcer caused by pressure from the jejunal tube was observed (Fig. 1B). The ulcer was along the axis of the tube from the pyloric antrum to the duodenal second portion without perforation (Fig. 1C). PEG-J tube was removed successfully with a snare but the remnant jejunal

Copyright $\odot 2020$ Korean College of Helicobacter and Upper Gastrointestinal Research

(a) The Korean Journal of Helicobacter and Upper Gastrointestinal Research is an Open-Access Journal. All articles are distributed under the terms of the Creative Commons Attribution Non-Commercial License (http:// creativecommons.org/licenses/by-nc/4.0) which permits unrestricted non-commercial use, distribution, and reproduction in any medium, provided the original work is properly cited. 
extension tube fell down toward the small intestine. Endoscope was inserted to the duodenal third portion, but the remnant tube was not found (Fig. 1D). There was no bleeding from the ulcer. She started 4-week administration of proton pump inhibitor as the same regimen for peptic ulcer, esomeprazole $40 \mathrm{mg}$ once a day by mouth. She restarted oral medication for idiopathic Parkinson's disease which she used to take before the initiation of carbidopa-levodopa in- fusion gel through the PEG-J. After 5 days, her symptoms subsided, and the remnant tube passed spontaneously with stool.

She finished 4-week treatment of proton pump inhibitor and underwent follow-up EGD; the ulcer healed (Fig. 2). She did not complain of symptoms associated with ulcer and did not have problems in having meals.
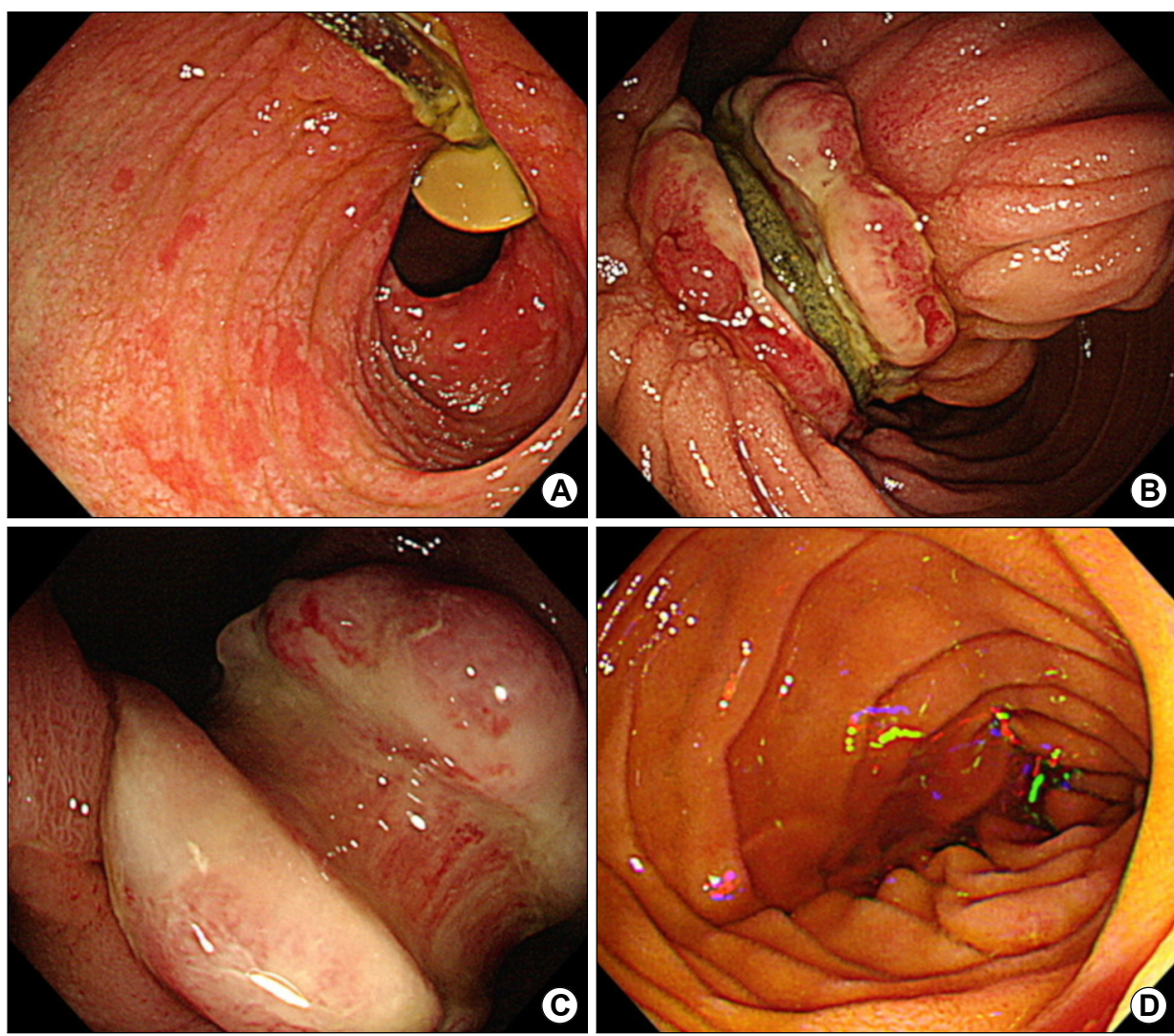

(B)
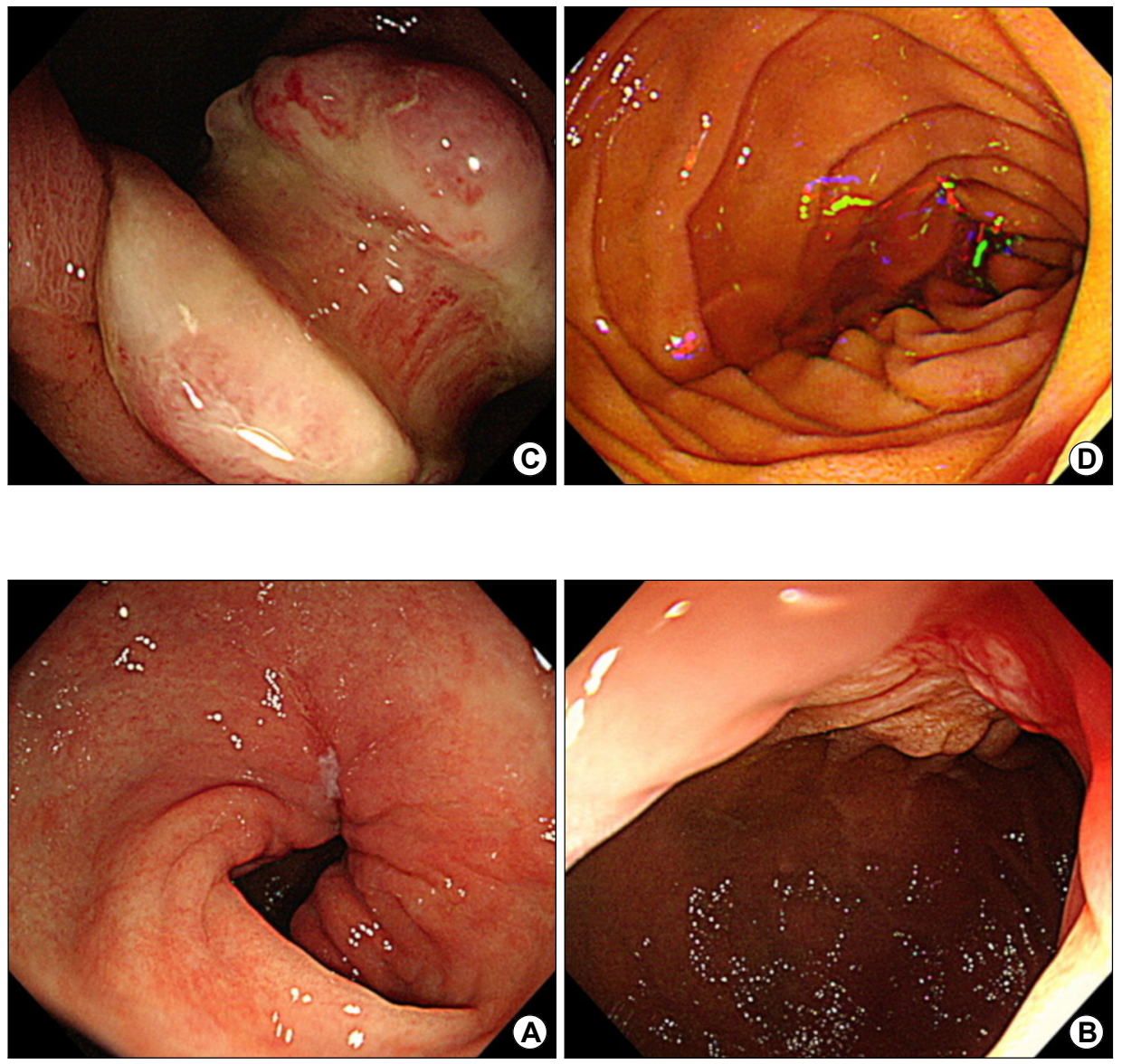

Fig. 1. Initial endoscopic findings. (A) The distal tip of the endoscope is placed in the proximal antrum. The inner bolster of percutaneous endoscopic transgastric jejunostomy (PEG-J) tube is expelled in the pylorus. (B) The distal tip is placed in the second portion of the proximal duodenum. The jejunal tube is inlaid with a deep and large longitudinal ulcer from the pyloric antrum to the second portion of the duodenum. (C) Duodenal decubitus ulcer with no bleeding or perforation after the successful removal of the PEG-J tube with a snare. (D) The endoscope is inserted in the third portion of the duodenum. There is no remnant tube and no ulcer in this part of the duodenum.

Fig. 2. Follow-up endoscopic findings 1 month later. (A, B) The healed ulcer and the scar are seen. 


\section{DISCUSSION}

For those who are unable to maintain adequate nutrition per oral, enteral feeding through a percutaneous approach is widely used. A jejunal route is preferred to gastric route in case of gastroparesis, gastric outlet obstruction and other functional or structural gastric problem with normal small bowel function. ${ }^{8}$ In addition, jejunal feeding decreased gastroesophageal regurgitation and aspiration pneumonia. 910 PEG-J, however, has a drawback, which is retrograde dislodgement up to $33 \%$ of cases. ${ }^{11}$ Surgical jejunostomy is an alternative option, if PEG-J procedure is unsuccessful. ${ }^{12}$ PEG-J is considered to have a lower complication rate compared with surgical jejunostomy.

Although PEG-J was first introduced more than 35 years ago, published reports of its long-term ( 7 to 30 days after tube insertion) complications are rather scant. PEG-J has several long-term complications due to jejunal extension tube compared with PEG, including dislocation (25.9 33.3\%), clogging (22.5 40.0\%), kinking (7.9\%), and tube defect $(16.7 \%)^{7,11}$

Decubitus ulcer caused by pressure from the PEG-J tube is a rare complication and its mechanism is uncertain. One case was reported that phytobezoar at the jejunal extension tube tip made a traction of the tube to cause decubitus in the duodenum. ${ }^{13}$ Unfortunately, we did not check the presence of phytobezoar in this case, because the remnant jejunal extension tube fell down toward the small intestine.

To the best of our knowledge, there are few reports of decubitus ulcer caused by PEG-J tube. ${ }^{13-15}$ Nevertheless, several cases of small bowel perforation caused by jejunal extension tube have been published. ${ }^{16-18}$ We assume that decubitus ulcer is seldom recognized early and is diagnosed when it causes perforation, because most of those who maintain enteral feeding via PEG-J are not able to complain of ulcer symptoms. The method to prevent such ulcer and risk factors has not been reported. Therefore, it is important to consider the possibility of decubitus ulcer if a patient with PEG-J has epigastric pain, dyspepsia, or weight loss.

The patient in this case presented with epigastric pain, dyspepsia, and weight loss. She underwent PEG-J 7 months ago for receiving carbidopa-levodopa infusion gel directly into the jejunum. The EGD showed that the jejunal tube was inlaid in a deep and large longitudinal ulcer without perforation. After removal of PEG-J and 4-week treatment of proton pump inhibitor, the ulcer healed, and symptoms were resolved.

In summary, duodenal decubitus ulcer caused by PEG-J tube is a rare complication and its diagnosis is challenging. Nonspecific symptoms such as dyspepsia or weight loss in those who have PEG-J could be a predictor of decubitus ulcer. We suggest that EGD is performed when patients with PEG-J complain of epigastric pain, dyspepsia, or weight loss and if decubitus ulcer caused by PEG-J tube is found, removal of PEG-J and proton pump inhibitor as the same regimen for peptic ulcer is recommended.

\section{CONFLICT OF INTEREST}

No potential conflict of interest relevant to this article was reported.

\section{ORCID}

$\begin{array}{ll}\text { Seokin Kang } & \text { (D) https://orcid.org/0000-0003-2228-6479 } \\ \text { Yuri Kim } & \text { (D https://orcid.org/0000-0003-4372-065X } \\ \text { Hee Kyong Na } & \text { (D) https://orcid.org/0000-0001-6764-9099 } \\ \text { Sun Ju Chung } & \text { (D) https://orcid.org/0000-0003-4118-8233 } \\ \text { Jeong Hoon Lee } & \text { (D) https://orcid.org/0000-0002-0778-7585 }\end{array}$

\section{REFERENCES}

1. Gauderer MW, Ponsky JL, Izant RJ Jr. Gastrostomy without laparotomy: a percutaneous endoscopic technique. J Pediatr Surg 1980;15:872-875.

2. Ponsky JL, Aszodi A. Percutaneous endoscopic jejunostomy. Am J Gastroenterol 1984;79:113-116.

3. Duckworth PF Jr, Kirby DF, McHenry L, DeLegge MH, FoxxOrenstein A. Percutaneous endoscopic gastrojejunostomy made easy: a new over-the-wire technique. Gastrointest Endosc 1994; $40: 350-353$.

4. Krones E, Zollner G, Petritsch W. Knotting of percutaneous endoscopic jejunostomy feeding tubes in two patients with Parkinson's disease and continuous Duodopa ${ }^{\circledR}$ treatment. Z Gastroenterol 2012;50:213-216.

5. Liao GS, Hsieh HF, Wu MH, Chen TW, Yu JC, Liu YC. Knot for- 
mation in the feeding jejunostomy tube: a case report and review of the literature. World J Gastroenterol 2007;13:973-974.

6. Myers A, Thurston W, Ho CS. Spontaneous knotting of a transgastric jejunostomy tube: case report. Can Assoc Radiol J 1997; 48:22-24.

7. Ridtitid W, Lehman GA, Watkins JL, et al. Short- and long-term outcomes from percutaneous endoscopic gastrostomy with jejunal extension. Surg Endosc 2017;31:2901-2909.

8. Jarnagin WR, Duh QY, Mulvihill SJ, Ridge JA, Schrock TR, Way LW. The efficacy and limitations of percutaneous endoscopic gastrostomy. Arch Surg 1992;127:261-264.

9. Heyland DK, Drover JW, MacDonald S, Novak F, Lam M. Effect of postpyloric feeding on gastroesophageal regurgitation and pulmonary microaspiration: results of a randomized controlled trial. Crit Care Med 2001;29:1495-1501.

10. Cech AC, Morris JB, Mullen JL, Crooks GW. Long-term enteral access in aspiration-prone patients. J Intensive Care Med 1995; 10:179-186.

11. Zopf Y, Rabe C, Bruckmoser T, Maiss J, Hahn EG, Schwab D. Percutaneous endoscopic jejunostomy and jejunal extension tube through percutaneous endoscopic gastrostomy: a retrospective analysis of success, complications and outcome. Digestion 2009;79:92-97.

12. Tapia J, Murguia R, Garcia G, de los Monteros PE, Oñate E. Jejunostomy: techniques, indications, and complications. World
J Surg 1999;23:596-602.

13. Cerrone P, Marchese M, Pistoia MA, Marini C. Phytobezoar and duodenal ulcer as complication of Duodopa therapy in a patient affected by Parkinson's disease. BMJ Case Rep 2018;2018: bcr2017223884.

14. Olivares A, Collado D, Muñoz-Navas M, et al. Complications of percutaneous endoscopic gastrostomy-jejunostomy for levodopa/carbidopa infusion in advanced Parkinson's disease. Gastroenterol Insights 2012;4:e4.

15. Martino T, Melchionda D, Tonti P, et al. Weight loss and decubitus duodenal ulcer in Parkinson's disease treated with levodopa-carbidopa intestinal gel infusion. J Neural Transm (Vienna) 2016;123:1395-1398.

16. Kalkan IH, Dişibeyaz S, Onder FO, et al. A rare complication of percutaneous endoscopic gastrojejunostomy (PEG-J): duodenal bulb perforation due to retrograde migration. Acta Gastroenterol Belg 2012;75:276-277.

17. Rosenberger LH, Newhook T, Mauro DM, Hennessy SA, Sawyer RG. Jejunal tube extensions via percutaneous endoscopic gastrostomy and delayed small-bowel perforations: a case series. Gastrointest Endosc 2012;75:683-687.

18. Zibetti M, Merola A, Artusi CA, et al. Levodopa/carbidopa intestinal gel infusion in advanced Parkinson's disease: a 7-year experience. Eur J Neurol 2014;21:312-318. 